\title{
Revisão do gênero Tynelia Stål e descrição de um novo gênero correlato (Hemiptera, Membracidae, Smiliinae) ${ }^{1}$
}

\author{
Antonio José Creão-Duarte ${ }^{2}$ \\ Albino M. Sakakibara ${ }^{3}$
}

\begin{abstract}
Revision of the genus Tynelia Stål and description of a correlated new genus (Hemiptera, Membracidae, Smiliinae). Tynelia Stål, 1858 is revised and its limits redefined; two species are included: $T$. longula Burmeister, 1835 (=Boethoos nitida Funkhouser, 1922, Syn.n.) and T. godoyae sp.n. (from Brazil, Pará). Neotynelia gen.n. (type species: Darnis pubescens Fabricius, 1803) is described and the following species are treated, as well as some nomenclatural changes introduced: Neotynelia pubescens (Fabricius, 1803) comb.n. (= Tragopa prominens Walker, 1858 Syn.n.; = Boethoos hirsuta Funkhouser, 1922 Syn.n.; = Boethoos cinctata Haviland, 1925, Syn.n.); Neotynelia vertebralis (Fairmaire, 1846) sp. reval., comb.n. (= Tragopa bilinea Walker, 1858 Syn.n.; = Boethoos brunnea Funkhouser, 1922 Syn.n.); Neotynelia distinguenda (Fowler, 1895), sp. reval., comb.n.; Neotynelia nigra (Funkhouser, 1940) comb.n. (= Tynelia flavodorsata Fonseca, 1941 Syn.n.); Neotynelia bandeirai sp.n., Neotynelia martinsi sp.n., and Neotynelia rafaeli sp.n. (all three new species from Brazil, Mato Grosso).

KEY WORDS. Hemiptera, Membracidae, Smiliinae, Tynelia, taxonomy
\end{abstract}

BURMEISTER (1835) redescreveu o gênero Entylia Germar, 1833 e incluiu nele $E$. longula; no ano seguinte (BURMEISTER 1836), acrescentou mais três espécies: E. dispar, E. sellata e E. triguttata.

Fairmaire (1846) descreveu o gênero Parmula considerando as seguintes espécies: $P$. bistrigata, $P$. vertebralis e $P$. gibbula. Comentou que este gênero correspondia provavelmente a Entylia de Burmeister.

STÅL (1858) isolou a espécie Entylia longula Burmeister das outras do gênero e, com base nela, criou o gênero Tynelia. Mais tarde (STÅL 1869) redescreveu as espécies de Fabricius e, dentre elas, Darnis pubescens que foi transferida para o gênero Tynelia.

KIRKALDY (1902) descobriu que Parmula Fairmaire era um nome pré-ocupado e, por isso, propôs um novo nome, Harmonides. Dois anos depois, ele próprio (KIRKALDY 1904), inadvertidamente, propôs novamente um nome para substituir Parmula de Fairmaire, desta vez como Boethoos. Este segundo nome passou a ser utilizado por alguns autores. METCALF (1952) esclareceu que o nome Harmonides Kirkaldy tinha prioridade sobre Boethoos Kirkaldy e, ao mesmo tempo, designou a

1) Contribuição número 1152 do Departamento de Zoologia, Universidade Federal do Paraná.

2) Departamento de Sistemática e Ecologia, Universidade Federal da Paraíba. 58059-900 João Pessoa, Paraiba, Brasil.

3) Departamento de Zoologia, Universidade Federal do Paraná. Caixa Postal 19020, 81531-990 Curitiba, Paraná, Brasil. Bolsista do CNPq. 
sua espécie-tipo. Os limites genéricos, tanto de Tynelia como de Parmula (= Harmonides) não ficaram bem definidos tanto que, até recentemente, as espécies eram colocadas ora em um, ora em outro gênero. FUNKHOUSER (1922) descreveu Boethoos brunnea. Haviland (1925), tratando dos membracídeos da Guiana, descreveu Boethoos cinctata e B. globosa. FunKHOUSER (1927), em seu catálogo, fez constar Tynelia Stål e Boethoos Kirkaldy, ignorando a existência do gênero Harmonides Kirkaldy.

FunKHOUSER $(1935 ; 1940)$ e FonSECA (1941) acrescentaram mais três espécies, desta vez em Tynelia, respectivamente: T. cerulea, T. nigra e T. flavodorsata.

METCALF \& WADE (1965) colocaram em Tynelia: T. cerulea, T. cinctata, T. flavodorsata, $T$. globosa, $T$. hirsuta, $T$. longula, $T$. nigra, $T$. nitida, $T$. prominens, T. pubescens e T. tumulata. Situou o gênero dentro de Polyglyptini.

DEITZ (1975), ao reclassificar os membracídeos, considerou Tynelia dentro de Amastrini.

SAKAKIBARA (1996) transferiu Tynelia tumulata (Buckton, 1903) para o gênero Maturnaria, considerando-a como sinônimo de M. ephippigera (Fairmaire, 1846). SAKAKIBARA (1998) transferiu Parmula curvispina Walker, 1858, colocada por METCALF \& WADE (1965) em Thrasymedes, para o gênero Tapinolobus Sakakibara.

CREÃO-DUARTE (1999) observou que Tynelia cerulea não pertencia à Smiliinae-Amastrini, e sim à Darninae-Darnini; fez a sua transferência e, ao mesmo tempo, criou o gênero Funkhouseriana para acomodar a espécie.

Abreviaturas utilizadas no texto: (BMNH) The Natural History Museum, Londres; (CCBM) Coleção Carlos Bordón, Maracay, Venezuela; (DSE/UFPB) Departamento de Sistemática e Ecologia, Universidade Federal da Paraíba; (DZUP) Departamento de Zoologia, Universidade Federal do Paraná; (INPA) Instituto Nacional de Pesquisas da Amazônia; (Lund) Lund University, Lund Museum, Suécia; (USNM) National Museum of Natural History, Washington, DC.

\section{Tynelia Stål, 1858}

Tynelia Stål, 1858: 250 (Espécie-tipo: Entylia longula Burmeister, 1835; desig. orig.). - Stål, 1869: 29. - Metcalf \& Wade, 1965: 883. - Deitz, 1975: 94. - Creão-Duarte, 1999: 905.

Descrição de STÅL (1858): "Corpo bastante oblongo-ovalado, pouco piloso. Cabeça grande, triangular, projetada, fronte convexa, quase toda inflexa, com um tufo densamente piloso no ápice. Tórax transversalmente convexo, convexo-subdeclivado anteriormente, para trás bastante projetado, ultrapassando o abdome e cobrindo-o totalmente, ápice levemente agudo, acima da base das tégminas, a cada lado, profundamente sinuado, e daí para trás levemente mais alargado. Tégminas com cinco células apicais das quais a terceira é formada por uma veia bifurcada, três discoidais (2.1) e três basais, das quais a costal bastante alongada, estreita, dilatada no ápice. Tíbias prismáticas. Tarsos posteriores ligeiramente mais longos que os anteriores. O gênero fica próximo de Parmula e Acutalis." 
Acrescentam-se à descrição de Stål, mais as seguintes características: cabeça alongada, fortemente projetada para frente, de superfície lisa e convexa; lóbulos supra-antenais grossos, com os bordos arredondados; pós-clípeo cônico, mais longo que largo, estendendo-se à frente dos lóbulos supra-antenais (Fig. 3). Pronoto alongado, largamente arqueado, levemente acinturado depois dos ângulos umerais.

Comentários. Este gênero é caracterizado pela forma geral da cabeça que é mais longa que larga entre os olhos, com os lóbulos supra-antenais engrossados e o pós-clípeo distintamente cônico.

\section{Tynelia longula (Burmeister, 1835)}

Figs 1,3

Entylia longula Burmeister, 1835: 143 (Loc.-tipo: Brasil, Pará).

Boethoos nitida Funkhouser, 1922: 25 (Loc.-tipo:Peru). Syn.n.

Tynelia longula; Metcalf \& Wade, 1965: 884.

Tynelia nitida; Metcalf \& Wade, 1965: 885.

BURMEISTER (1836) apresentou a seguinte caracterização: "Pronoto liso, brilhante, fina porém profundamente pontuado; cabeça muito saliente, sobretudo a fronte que é recurvada para baixo e munida de um tufo de pelos em forma cônica; asas hialinas, as anteriores um pouco mais longas que a extremidade do pronoto, tendo à base do bordo anterior e à extremidade uma mancha castanho-enegrecida; pernas sem caracteres distintivos; abdome mais curto que as asas e pronoto."

Medidas (mm). Fêmea/macho. Comprimento total 5,77/5,38; largura da cabeça 2,05/2,15; distância entre os ângulos umerais 2,25/2,35.

Diagnose. Cabeça, em vista lateral, com a distância do ápice do pós-clípeo ao olho menor que o diâmetro maior do olho.

Macho. Coloração geral castanho-escura. Cabeça triangular, pouco mais larga entre os olhos que longa medianamente, lisa, brilhante e pilosa; lóbulos supra-antenais com o ápice ligeiramente anguloso junto ao pós-clípeo. Pronoto largamente convexo, fracamente acinturado depois dos ângulos umerais, terminando pouco antes do ápice das tégminas entre a terceira célula e o bordo distal.

Fêmea. Semelhante ao macho, um pouco maior; pronoto ligeiramente mais curto, terminando pouco antes do final da terceira célula apical.

Material examinado: BRAsil: Amazonas (INPA); Mato Grosso (DZUP); Pará (DSE/UfPB); Paraiba (DSE/UfPB). PERU: Rio Napo (USNM).

Boethoos nitida Funkhouser, 1922 (Holótipo fêmea, USNM).

Comentários. Os exemplares estudados, embora muito poucos, mostraram uma pequena variação no tamanho. A coloração, em geral, é castanho-escura bastante uniforme mas verificamos alguns exemplares com o pronoto castanho-claro com uma mancha escura no dorso.

O desenho apresentado por BURMEISTER (1836) ajuda bastante na identificação da espécie; mostra que a cabeça é mais curta que larga, com o pós-clipeo ovóide e projetado para frente; permite visualizar ainda, a forma ligeiramente angulosa dos lóbulos supra-antenais junto do pós-clípeo. 


\section{Tynelia godoyae, sp.n.}

Fig. 2

Medidas (mm). Fêmea/macho. Comprimento total: 6,84/6,46. Largura da cabeça: 2,09/2,00. Distância entre os ângulos umerais: 2,47/2,37

Diagnose. Cabeça, em vista lateral, com a distância do ápice do pós-clipeo ao olho, maior que o diâmetro maior do olho.

Holótipo fêmea. Coloração geral castanho-escura. Cabeça triangular, ligeiramente mais longa medianamente que a largura entre os olhos; superfície lisa e brilhante, pilosa; pós-clípeo ovóide, densamente piloso no ápice; lóbulos supra-antenais com o contorno contínuo e uniforme com o do pós-clípeo. Pronoto largamente convexo, em vista superior gradualmente afilado para o ápice, fracamente acinturado depois dos ângulos umerais, terminando quase junto com o ápice das tégminas. Tégminas hialinas com mancha escura apical, junto à margem costal, desde a primeira célula apical.

Macho. Semelhante à fêmea, ligeiramente menor.

Material examinado. Holótipo fêmea de "SINOP- M. Grosso/ Brasil-X.1975/ M. Alvarenga" (DZUP). Parátipos: 3 machos e 1 fêmea com os mesmos dados do holótipo. (DZUP; DSE/UFPB).

Comentários. Esta espécie é muito parecida com T. longula; difere principalmente na forma da cabeça, apresentando o pós-clípeo bastante alongado e cônico. Etimologia. Espécie dedicada à Dra. Carolina Godoy do INBIO.

\section{Neotynelia gen.n.}

Espécie-tipo: Darnis pubescens Fabricius, 1803.

Diagnose. Cabeça obliquamente projetada para frente, aproximadamente tão longa quanto larga entre os olhos; lóbulos supra-antenais laminares, com os bordos distintamente levantados.

Cabeça de superfície lisa, brilhante e pilosa, de forma triangular, aproximadamente tão longa quanto larga entre os olhos; vértice ligeiramente convexo no meio; olhos globosos, mais ou menos salientes; ocelos conspícuos, ligeiramente mais próximos dos olhos que entre si, situados abaixo da linha imaginária que passa pelo centro dos olhos; lóbulos supra-antenais laminares, com os bordos mais ou menos levantados deixando acentuadamente concavada a área abaixo dos ocelos; pós-clípeo ovóide, pouco saliente, com densa pilosidade no ápice (Figs 4,5). Pronoto largamente convexo, cobrindo aproximadamente $2 / 3$ das tégminas mas não atingindo o ápice das mesmas, densamente pontuado e piloso; carena noto-pleural fraca; lóbulos pós-oculares arredondados e ajustados ao corpo. Tégminas hialinas, com manchas escuras no ápice; venação bem distinta, com as veias $\mathrm{R}$ e $\mathrm{M}$ unidas ao longo do terço basal; célula subcostal alongada, ultrapassando o meio, estreita e subitamente alargada distalmente; célula discoidal $\mathrm{R}_{2}+3$ aproximadamente quatro vezes mais longa que larga, disposta obliquamente; com transversas $\mathrm{s}$ e duas $\mathrm{m}$-cu. Asas hialinas, com quatro células apicais, a segunda peciolada. Pernas normais; tíbias prismáticas, as anteriores ligeiramente dilatadas para o ápice; tíbias-III e basitarsos-III com cúculos setíferos. 


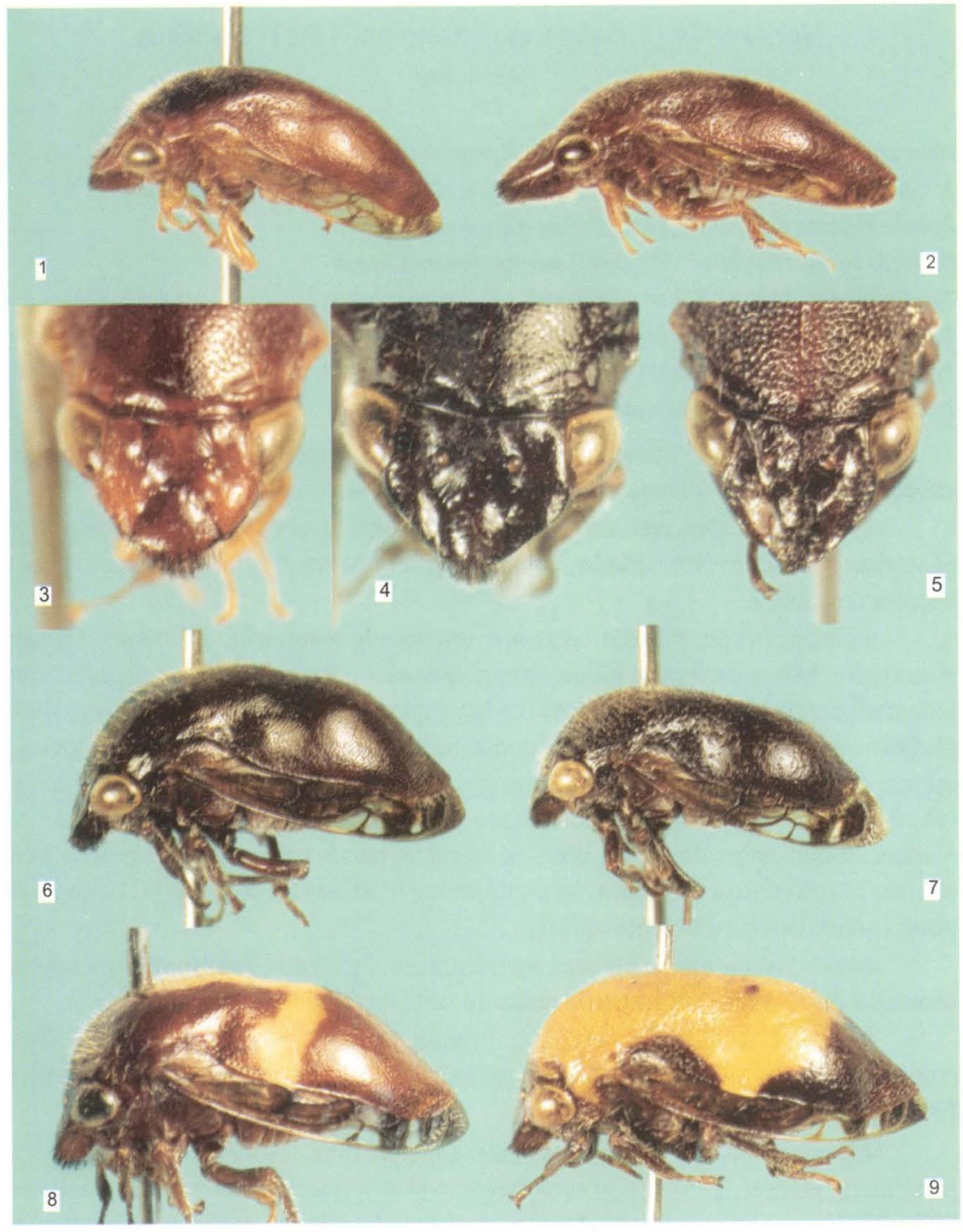

Figs 1-9. (1, 3) Tynelia longula; (2) Tynelia godoyae, holótipo fêmea; $(4,6,8,9)$ Neotynelia pubescens fêmeas, (7) macho; (5) Neotynelia nigra.

Comentários. Este gênero se assemelha muito a Tynelia Stål. A cabeça é menos projetada para frente e, em alguns casos, praticamente na vertical; os lóbulos supra-antenais são laminares e com os bordos levantados deixando a área abaixo dos ocelos bem côncava, mais ou menos em forma de colher; o pós-clípeo é mais ou menos ovóide e pouco saliente. O pronoto, em geral, é mais globoso e truncado distalmente. Há um leve dimorfismo sexual. Etimologia. Neo (= novo) + Tynelia (gênero com o qual tem grande semelhança). 


\section{Neotynelia pubescens (Fabricius, 1803) comb.n.}

Figs 4, 6-9

Darnis pubescens Fabricius, 1803: 29 (Loc.-tipo: América do Sul).

Tragopa prominens Walker, 1858: 151 (Loc.-tipo: Brasil). -Broomfield, 1971: 369. Syn.n.

Boethoos hirsuta Funkhouser, 1922: 25 (Loc.-tipo: Peru). Syn.n.

Boethoos cinctata Haviland, 1925: 249 (Loc.-tipo: Guiana). Syn.n.

Tynelia cinctata; Metcalf \& Wade, 1965: 883.

Tynelia hirsuta; Metcalf \& Wade, 1965: 884.

Tynelia prominens; Metcalf \& Wade, 1965: 885.

Tynelia pubescens; Metcalf \& Wade, 1965: 885.

Medidas (mm). Fêmea/macho. Comprimento total: 7,14/6,40. Largura da cabeça: 2,64/2,40. Distância entre os ângulos umerais: 3,23/2,80.

Diagnose. Cabeça pouco projetada para frente; pronoto globoso, com o terço posterior mais ou menos inflado, com a largura máxima aproximadamente igual à largura da cabeça.

Fêmea. Corpo robusto, densa e fortemente pontuado, brilhante. Cabeça pouco projetada para frente; lóbulos supra-antenais com os bordos moderadamente levantados; pós-clípeo ovóide quase tão largo quanto longo. Pronoto mais ou menos globoso, em vista lateral com o metopídio convexo, quase na vertical, o dorso mais ou menos na horizontal e no terço posterior abruptamente declinado para o ápice; em vista superior, levemente acinturado depois dos ângulos umerais e mais ou menos inflado antes do ápice, com as margens laterais levemente curvadas para dentro; porção apical ligeiramente tectiforme e acuminado, com a ponta atingindo pouco além da terceira célula apical.

Macho. Semelhante à fêmea, apenas um pouco menor. Pronoto abruptamente truncado distalmente, terminando antes do final da terceira célula apical.

Material examinado. Brasil: Amapá (DZUP); Amazonas (INPA); Pará (Dzup). Guiana (bmnh); Panamá (usnm); Venezuela: Zulia/Perija (usnm); PERU:Iquitos (USNM).

Darnis pubescens Fabricius, 1803 (apenas uma foto do síntipo) Tragopa prominens Wlaker, 1858 (Lectótipo macho, BMNH). Boethoos hirsuta Funkhouser, 1922 (Holótipo fêmea, USNM). Boethoos cinctata Haviland, 1925 (Holótipo fêmea, BMNH).

Comentários. T. pubescens é uma das espécies mais robustas do grupo. A coloração varia bastante mas, de um modo geral, é marrom-escura uniforme, principalmente nos machos. STÅL (1869) comentou, a respeito do macho, dizendo que o pronoto era negro concolorido com o ápice distintamente truncado. As fềmeas podem se apresentar com o pronoto quase inteiramente castanho-claro a amarelado, com o terço posterior escurecido; ou então com uma faixa transversal amarela cortando o pronoto de lado a lado, mais ou menos no meio, associado ou não com uma outra faixa longitudinal mediana que vai do metopídio até o terço posterior. 


\section{Neotynelia vertebralis (Fairmaire, 1846) sp. reval., comb.n. Figs $10-12$}

Parmula vertebralis Fairmaire, 1846: 491 (Loc.-tipo: América do Sul).

Tragopa bilinea Walker, 1858: 152 (Loc.-tipo: Brasil, Pará). -Metcalf \& Wade, 1965: 879 (= Harmonides dispar). - Broomfield, 1971: 335. Syn.n.

Boethoos brunnea Funkhouser, 1922: 26 (Loc.-tipo: Brasil, Pará). Syn.n.

Tynelia brunnea; Metcalf \& Wade, 1965: 884 (= Tynelia longula).

Harmonides reticulata var. vertebralis. - Metcalf \& Wade, 1965: 882.

Medidas (mm). Fêmea/macho. Comprimento total: 5,18/4,88. Largura da cabeça: 2,15/2,08. Distância entre os ângulos umerais: 2,45/2,40.

Diagnose. Coloração geral castanho-clara com uma faixa amarela dorsal ao longo da linha média do metopídio até o terço posterior onde emite ramos para os lados que podem atingir as margens laterais.

Fêmea. Em geral castanho-clara com mancha amarela dorsal nos dois terços anteriores, emitindo ou não ramos laterais; carena noto-pleural e margens dos lóbulos pós-oculares amarelas.

Material examinado. Brasil: Amazonas, Mato Grosso, Maranhão, Minas Gerais, Pará (DZUP); VENEZUELA (CCBM).

Tragopa bilinea Walker, 1858 (apenas a foto do holótipo fêmea; BMNH) Boethoos brunnea Funkhouser, 1922 (Holótipo fêmea, USNM).

Comentários. Esta espécie é semelhante a $T$. pubescens na sua forma geral mas de tamanho bem menor. A coloração varia bastante: há indivíduos quase totalmente amarelados ou então praticamente negros; comumente são acastanhados com mancha dorsal amarela não muito bem definida; os indivíduos escuros podem ter, a cada lado, uma mancha amarela. METCALF \& WADE (1965) consideraram $P$. vertebralis Fairmaire como sendo uma simples variedade de Harmonides reticulata (Fabricius, 1803). Verificou-se, entretanto, que P. vertebralis Fairmaire é uma espécie boa e pertencente ao gênero Tynelia Stål.

\section{Neotynelia distinguenda (Fowler, 1895) sp. reval., comb.n.}

Fig. 13

Parmula distinguenda Fowler, 1895: 91 (Loc.-tipo: México). -Metcalf \& Wade, 1965: 879 (= Harmonides dispar). - Broomfield, 1971: 346.

Boethoos distinguenda; Haviland, 1925: 250.

Medidas. Fêmea: comprimento total 6,00; largura da cabeça 2,28; distância entre os ângulos umerais 2,68.

Diagnose. Cabeça mais curta que larga entre os olhos; lóbulos supra-antenais com os bordos muito pouco levantados.

Fêmea. Coloração geral castanho-escura, com uma faixa transversa amarela, depois dos ângulos umerais, interrompida no meio; margens dos lóbulos supra-antenais e carena noto-pleural, amareladas. Cabeça curta e pouco concavada; lóbulos supra-antenais com os bordos muito pouco levantados.

Macho. Não examinado.

Material examinado. PANAMÁ (DZZUP).

Parmula distinguenda Fowler, 1895 (apenas foto do lectótipo fềmea; BMNH). 
Comentários. Esta espécie é muito parecida com $N$. vertebralis, diferindo principalmente na forma da cabeça que é distintamente mais curta que larga entre os olhos e mais plana. $\mathrm{O}$ escasso material disponível não permite avaliar a variação do colorido geral, mas FOWLER (1895) comentou que não observou grandes variações. METCALF \& WADE (1965) incluíram P. distinguenda Fowler em Harmonides Kirkaldy e como sinônimo júnior de $H$. dispar (Fabricius, 1803).

\section{Neotynelia nigra (Funkhouser, 1940) comb.n.}

\section{Figs 5,14}

Tynelia nigra Funkhouser, 1940: 287 (Loc.-tipo: Peru). - Metcalf \& Wade, 1965: 885.

Tynella [sic] flavodorsata Fonseca, 1941: 136 (Loc.-tipo: Brasil, Pará). Syn.n.

Tynelia flavodorsata; Metcalf \& Wade, 1965: 884.

Medidas (mm). Fêmea/macho. Comprimento total: 7,14/6,95. Largura da cabeça: 2,25/2,15. Distância entre os ângulos umerais: 2,74/2,54.

Diagnose. Cabeça alongada, projetada para frente, lóbulos supra-antenais com os bordos bem levantados; pronoto afilado para trás e quase atingindo o ápice das tégminas.

Fêmea. Coloração geral castanho-escura. Cabeça aproximadamente tão longa quanto larga entre os olhos; lóbulos supra-antenais bem desenvolvidos, com os bordos bem levantados acentuando a concavidade da cabeça; pós-clípeo, devido à depressão junto aos lóbulos supra-antenais, aparentando bem mais longo que largo. Pronoto largamente convexo, em vista lateral com a linha de contorno acompanhando a da cabeça; em vista superior muito pouco acinturado após os ângulos umerais e gradativamente afilado em direção à extremidade; ápice acuminado, ligeiramente tectiforme, atingindo quase a extremidade das tégminas.

Macho. Semelhante à fêmea, ligeiramente menor.

Material examinado. BRASIL (USNM); COLOMBiA (USNM); EQUAdOR (USNM); PERU (USNM, LUND); SURINAME (BMNH).

Tynelia nigra Funkhouser, 1940 (Holótipo fêmea, USNM).

Comentários. Esta espécie se distingue das demais pela cabeça fortemente projetada para frente, com os lóbulos supra-antenais bem desenvolvidos e levantados acentuando a concavidade. O pronoto é alongado, afilado distalmente, com o ápice quase atingindo a extremidade das tégminas. A coloração geral sofre uma pequena variação: de castanho-clara a quase inteiramente escura; em alguns casos com uma faixa amarela percorrendo longitudinalmente o dorso, podendo se estender para a cabeça; carena noto-pleural concolorida ou amarela, como acontece com $T$. flavodorsata Fonseca.

\section{Neotynelia bandeirai, sp.n.}

Fig. 15

Medidas (mm). Fêmea/macho. Comprimento total: 5,58/5,28. Largura da cabeça: 2,05/2,05. Distância entre os ângulos umerais: 2,35/2,35.

Diagnose. Cabeça e parte do metopídio, negras. Pronoto pouco elevado, com o dorso horizontal e abruptamente em declive no terço apical. 


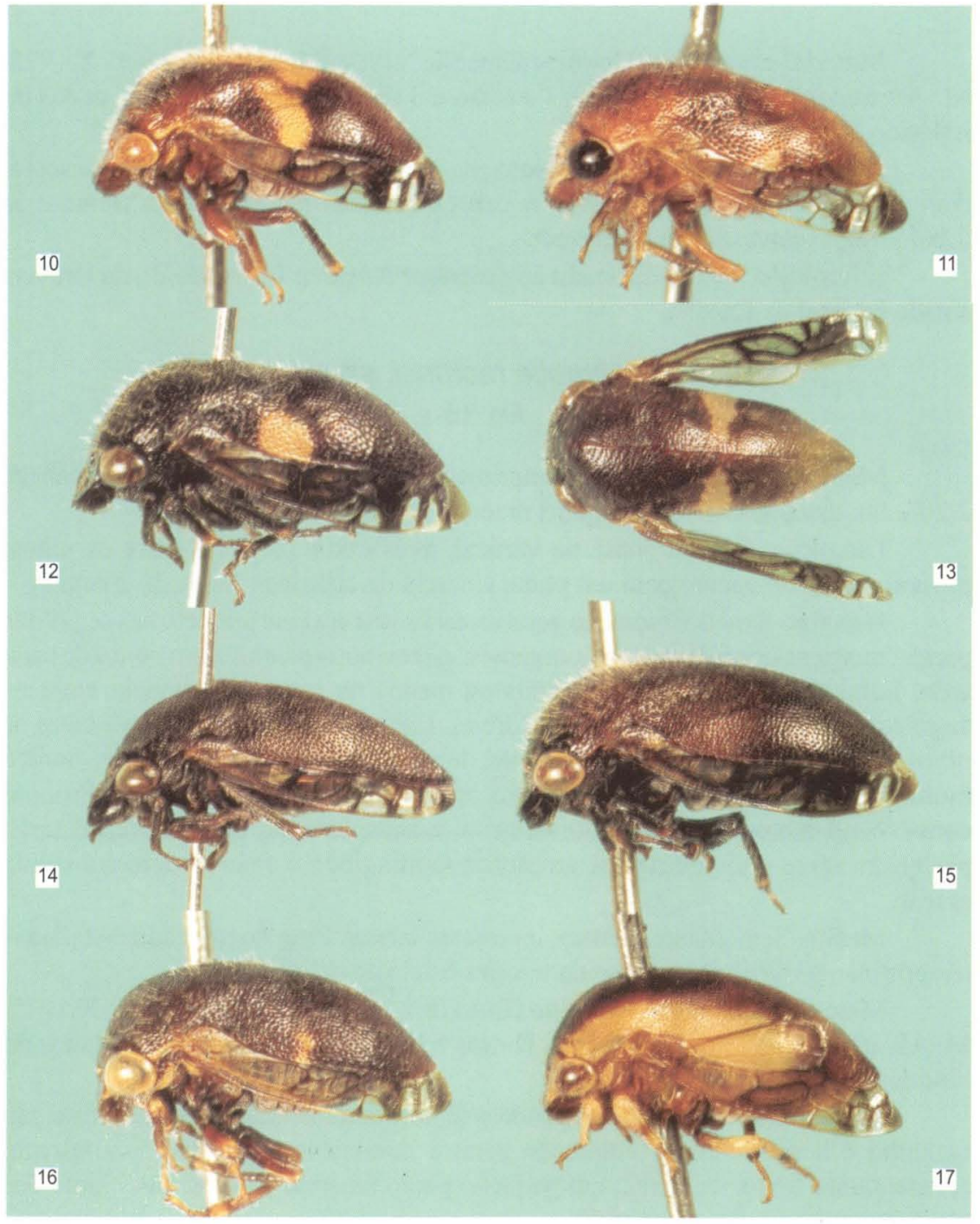

Figs 10-17. (10,12) Neotynelia vertebralis fêmeas, (11) macho; (13) Neotynelia distinguenda; (14) Neotynelia nigra; (15) Neotynelia bandeirai, holótipo fêmea; (16) Neotynelia martinsi, holótipo fêmea; (17) Neotynelia rafaeli, holótipo fêmea.

Holótipo fêmea. Coloração geral castanho-escura; cabeça e parte do metopídio, negras; carena noto-pleural amarelada. Cabeça lisa, brilhante; lóbulos supraantenais com os bordos mais ou menos levantados. Pronoto pouco elevado, quase horizontal no dorso, abruptamente em declive perto do ápice; em vista superior um pouco acinturado depois dos ângulos umerais e com os lados quase paralelos até o terço apical.

Macho. Semelhante à fêmea, apenas menor. 
Material examinado: Holótipo fềmea de "SINOP- M. Grosso/ Brasil - X.1975/ M. Alvarenga" (DZUP). Parátipos: 1 macho e 3 fềmeas com os mesmos dados do holótipo.(DZUP).

Comentários. Espécie muito parecida com $N$. vertebralis porém mais escura, com a cabeça e metopídio negros. A cabeça é menos projetada para frente e os lóbulos supra-antenais pouco elevados.

Etimologia. Nome dedicado ao professor Adelmar G. Bandeira, da Universidade Federal da Paraíba.

\section{Neotynelia martinsi, sp.n.}

Fig. 16

Medidas. Fêmea/macho. Comprimento total 4,96/4,64; largura da cabeça 2,20/2,00; distância entre os ângulos umerais 2,48/2,28.

Diagnose. Cabeça quase na vertical, mais curta que larga entre os olhos; pronoto castanho-escuro com um ponto amarelo de cada lado junto das margens.

Holótipo fêmea. Coloração geral castanho-escura com amarelo nas seguintes partes: margens dos lóbulos supra-antenais, carena noto-pleural e um ponto de cada lado, junto das margens laterais, mais ou menos no meio da distância entre os ângulos umerais e o ápice, e parte das tíbias. Cabeça mais curta que larga entre os olhos, posicionada quase verticalmente; lóbulos supra-antenais com os bordos muito fracamente levantados tornando a cabeça plana, sem concavidade. Pronoto convexo no metopídio, plano dorsalmente e abruptamente em declive no terço posterior; ápice mais ou menos arredondado atingindo o final da terceira célula apical.

Macho. Semelhante à fêmea, levemente menor. Pronoto truncado distalmente, terminando na altura da base da terceira célula apical

Material examinado. Holótipo fêmea de "SINOP - M. Grosso/ Brasil-X.1975/ M. Alvarenga" (DZUP). Parátipos: 5 fềmeas e 6 machos com os mesmos dados do holótipo (DZUP).

Comentários. A forma do pronoto lembra a de $N$. pubescens porém o seu tamanho é bem menor. A coloração geral é homogeneamente castanho-escura, apresentando frequentemente, um pequeno ponto amarelo de cada lado, junto das margens, mais ou menos no meio.

Etimologia. Espécie dedicada ao professor Celso Feitosa Martins, da Universidade Federal da Paraíba.

\section{Neotynelia rafaeli, sp.n.}

Fig. 17

Medidas. Fêmea. Comprimento total 6,40; largura da cabeça 2,40; distância entre os ângulos umerais 2,72 .

Diagnose. Cabeça pouco projetada para frente, mais curta que larga entre os olhos, mais ou menos plana; pronoto castanho-escuro com uma faixa amarela, larga, de cada lado estendida desde a cabeça até o terço posterior. 
Holótipo fêmea. Coloração geral castanho-escura com as seguintes partes amarelas: uma larga faixa de cada lado partindo da cabeça e passando pelos ângulos umerais até o terço posterior; bordos dos lóbulos pós-oculares e pernas, exceto as bases, e um anel pré-apical nas tíbias. Cabeça mais curta que larga entre os olhos; lóbulos supra-antenais com os bordos não levantados deixando a cabeça praticamente plana, sem concavidade.

Macho. Desconhecido.

Material examinado. Holótipo fêmea de "BRASIL: Mato Grosso/ Reserva Humboldt/ $10^{\circ} 11^{\prime}$ 'S. 59 48'O/ 18-III-1977/ Norman D. Penny".

Comentários. Esta espécie é muito parecida com $N$. pubescens, tanto no tamanho como na forma geral do corpo. Difere pela cabeça mais plana e pela presença das faixas amarelas.

Etimologia. Espécie dedicada ao Dr. José Albertino Rafael, do INPA, Manaus.

\section{REFERÊNCIAS BIBLIOGRÁFICAS}

Broomfield, P.S. 1971. A catalogue of the membracid types (Homoptera: Membracidae:) in the British Museum (Natural History). Bull. British Mus. (N.H.), Entomology, 25 (8): 325-386.

Burmeister, H.C.C. 1835. Schnabelkerfe. Rhynchota. Handbuch der Entomologie 2 (1): 1-396. - 1836. Monographie du genre Darnis. Rev. Ent. Silbermann 4: 164-191.

Crfão-DuartF, A.J. 1999. Funkhouseriana, um novo gênero de Darninae (Hemiptera, Membracidae).

Revta bras. Zool. 16 (3): 905-908.

DEITZ, L.L. 1975. Classification of the higher categories of the New World treehoppers (Homoptera:

Membracidae). North Carolina Agric. Experim. Stat. Tech. Bull. 225: 1-177.

FABRICIUS, J.C. 1803. Rhyngota. Systema Rhyngotorum secundum ordines, genera, species, adiectis synonymis, locis, observationibus, descriptionibus. $101 \mathrm{p}$.

Fairmairf, L.M.H. 1846. Revue de la tribu des Membracides. Ann. Soc. Ent. France 4: 479-531.

FonSECA, J.P. DA. 1941. Contribuição para o conhecimento dos membracideos neotrópicos (IV). Arq.

Instituto Biológico 12: 129-140.

Fowler, W.W. 1895. Order Rhynchota. Suborder Hemiptera-Homoptera. (Cont.). Biologia Centrali-Americana 2: 57-128.

FunkHousER, W.D. 1922. New records and species of south american Membracidae. Jour. N.Y. Ent. Soc. 30 (1): 1-35.

- 1927. Membracidae. General Catalogue of the Hemiptera. Massachussets, Smith College, $581 \mathrm{p}$.

- 1935. New Membracidae in the Imperial Institute Collection. Jour. N.Y. Ent. Soc. 53: 427-435.

1940. New peruvian Membracidae (Homoptera). Jour. N.Y. Ent. Soc.

58: $275-293$.

H^VILAND, M.D. 1925. The Membracidae of Kartabo. Bartica District, British Guiana.With descriptions of new species and bionomical notes. Zoologica 6 (3): 229-290.

KIRKALdY, G.W. 1902. Miscellanea Rhynchotalia. 5. Entomologist 35: 315-316.

- 1904. Bibliographical and nomenclatorial notes on the Hemiptera. 3. Entomologist 37: 279-283.

Metcalf, Z.P. 1952. New names in the Homoptera. Jour. Wash. Acad. Sci. 42: 226-231.

MetCalf, Z.P. \& V. WADE. 1965. General Catalogue of the Homoptera. Membracoidea. Sec. II.

Raleigh, North Carolina State University, p. 745-1552.

SaKakibara, A.M. 1996. Taxonomic notes on some Polyglyptini: descriptions of new genus and new 
species (Homoptera, Membracidae, Smiliinae). Revta bras. Zool. 13 (2): 463-474.

1998. The tribe Acutalini Fowler (Homoptera, Membracidae, Smiliinae): new genera, new species and some nomenclatural changes. Revta bras. Zool. 14 (3): 659-674.

STÅL, C. 1858. Nagra nya genera och bland Hemiptera. Öfver. Svenska Vet. Akad. Forh. 15: 248-250. 1869. Hemiptera Fabriciana. Svenska Vetenskaps Akadem. Forhand. 8: 1-130.

WALKER, F. 1858. Supplement. List of the specimens of Homopterous insects in the collection of the British Museum: 1-307.

Recebido em 27.V.1999; aceito em 03.III. 2000. 